\title{
An Intercomparison of Pressure Standards Between LNE and NBS
}

\author{
R. G. Driver*, J. C. Houck*, and B. E. Welch* \\ National Bureau of Standards, Washington, DC 20234
}

January 7, 1981

\begin{abstract}
An intercomparison between a transfer piston gage used by the Laboratoire National d'Essais (LNE) and a primary standard piston gage of the National Bureau of Standards was performed over the range of pressure of 0.4 to $3.9 \mathrm{MPa}$. The agreement between the computation of the effective area of the LNE gage by the two laboratories was within $6.4 \mathrm{ppm}$ and the agreement between the average of the pressures generated by these two gages was within $3.3 \mathrm{ppm}$, well below the estimated uncertainty of either gage (NBS $30 \mathrm{ppm}$ and LNE $24 \mathrm{ppm}$ ).
\end{abstract}

Key words: Effective area; intercomparison; piston gage; pressure; primary standard; transfer standard.

An intercomparison of pressures generated by a transfer piston gage placed at the Laboratoire National d'Essais (LNE)'s disposal by the Bureau National de Metrologie (BNM) and by a primary standard piston gage of the $\mathrm{Na}$ tional Bureau of Standards was performed at NBS over the pressure range 0.4 to $3.9 \mathrm{MPa}$.

The two gages differ somewhat in principle. The LNE gage is a simple piston and cylinder calibrated against a standard whose effective area is the average of the measured area of a piston and of a cylinder with theoretically calculated corrections of the pressure deformation of the piston and dilation of the cylinder. The NBS gage is a primary standard controlled clearance piston gage with the effective area derived from the measurement of the piston only, with an empirically determined correction based on the extrapolation of jacket pressure required to close the cylinder on the piston, and a theoretical pressure correction applied to deformation of the piston only. At the pressures at which this intercomparison was made, the pressure correction is small. At maximum pressure the fractional change in area for the LNE gage is $3.2 \times 10^{-6}$ and for the NBS gage is $-2.0 \times 10^{-6}$.

The NBS controlled clearance piston gage is gas operated with a piston of tungsten carbide with a diameter of 25.4 $\mathrm{mm}$ and a mating cylinder of tool steel. The effective area of the gage at $23{ }^{\circ} \mathrm{C}$ is $5.067819 \times 10^{-4} \mathrm{~m}^{2}$. The thermal coefficient of expansion of the carbide is $4.3 \times 10^{-6} /{ }^{\circ} \mathrm{C}$ and of the

•Center for Absolute Physical Quantities, National Measurement Laboratory. steel is $1.2 \times 10^{-5} /{ }^{\circ} \mathrm{C}$ so that the temperature coefficient of the effective area is $1.6 \times 10^{-5} /{ }^{\circ} \mathrm{C}$. The change in effective area due to pressure is $-5.07 \times 10^{-7} / \mathrm{MPa}$.

The LNE piston gage is oil operated with a piston diameter of approximately $8.0 \mathrm{~mm}$, and both piston and cylinder are tungsten carbide with a thermal coefficient of expansion of $4.1 \times 10^{-6} /{ }^{\circ} \mathrm{C}$. The temperature coefficient of the effective area is $8.2 \times 10^{-6} /{ }^{\circ} \mathrm{C}$ and the pressure coefficient is $8.0 \mathrm{x}$ $10^{-7} / \mathrm{MPa}$. The effective area at atmospheric pressure is $5.02724 \times 10^{-5} \mathrm{~m}^{2}$ at $20^{\circ} \mathrm{C}$.

The two gages and their connection through a coaxial capacitor gas/oil separator are shown schematically in figure 1. The interface between the oil used in the LNE gage and the dry nitrogen used in the NBS gage was monitored by a capacitance detector. This device $[1]^{1}$ utilized the difference in dielectric constants between the oil and the gas to measure the height of the interface. This permitted adequate sensitivity to not only account for the hydrostatic head in the fluid but also to detect the small changes in level that are necessary for a rapid determination of the proper balance of the two gages.

The calculations for pressure measurements by both controlled clearance piston gages and simple piston and cylinder piston gages, as well as considerations of direct comparison, are given by Heydemann and Welch [2]. The two gages were set up with the oil/gas interface at the same level as the bottom of the LNE piston at its operating level.

'Figures in brackets indicate literature references at the end of this paper. 
NBS CONTROLLED CLEARANCE

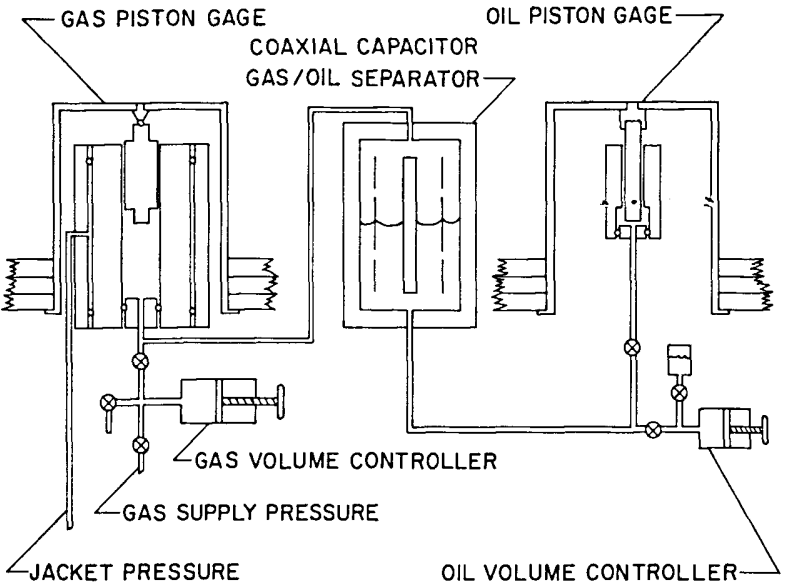

Ficure 1. A schematic drawing of the two gages with the gas/oil separator.

A head correction (for nitrogen) was applied for the difference in level between the bottom of the NBS piston at its operating level and the level of the oil in the separator. The gages were operated at temperatures near $23^{\circ} \mathrm{C}$ and the appropriate corrections were applied.

A total of 23 comparisons at 10 different pressures were made over a period of three days. One method of evaluating the data was the use of an NBS computer program for calculating the effective area of a piston gage to various orders of fits from the direct comparison of the test gage against a standard piston gage. The results of the lowest order FIT routine $(F=P A)$ used for this gage give an effective area of the LNE gage of $5.027396 \times 10^{-5} \mathrm{~m}^{2}$ at $23{ }^{\circ} \mathrm{C}$. This FIT routine gave three sigma of the calculation of the area to be $7.2 \mathrm{ppm}$ of the area. The area of the LNE gage given by LNE is $5.027364 \times 10^{-5} \mathrm{~m}^{2}$ at $23^{\circ} \mathrm{C}$. This difference in area of the LNE gage determined by the NBS standard in this comparison with that given by LNE is $6.4 \mathrm{ppm}$ in area.

Another method of evaluating the intercomparison was the calculation of the pressure generated by each piston gage according to the method used by the respective laboratories. The results of the 23 direct comparisons (the same points as used in the first method) are shown in table 1 . The pressures were calculated for the pressure at the nitrogen oil interface. The average of the pressure calculated by LNE minus the pressure calculated by NBS is $13.0 \mathrm{~Pa}$ with a standard deviation of the mean of $5.8 \mathrm{~Pa}$. The average of the pressure calculated by LNE minus the pressure calculated by NBS divided by the NBS pressure is $3.3 \mathrm{ppm}$ with a standard deviation of the mean of $4.2 \mathrm{ppm}$. A plot of the differences in pressure calculated from the two gages versus the pressure is shown in figure 2 . No quantitative explanation is given for the indicated systematic shift. It is due to using empirically determined non-smoothed values for the
TABLE 1. Comparison of Pressures Generated by NBS and LNE in Chronological Order.

\begin{tabular}{|c|c|c|c|}
\hline \multicolumn{2}{|c|}{ Pressure by } & \multirow{2}{*}{ 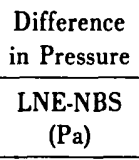 } & \multirow{2}{*}{\begin{tabular}{|c} 
Difference in Pressure \\
Pressure \\
$\frac{\text { LNE-NBS }}{\text { NBS }}$ \\
\end{tabular}} \\
\hline $\begin{array}{l}\text { NBS } \\
(\mathrm{Pa})\end{array}$ & $\begin{array}{l}\text { LNE } \\
(\mathrm{Pa}) \\
\end{array}$ & & \\
\hline 389874.6 & 389858.1 & -16.5 & $-42.3 \times 10^{-6}$ \\
\hline 1169566.0 & 1169562.2 & -3.8 & $-3.3 \times 10^{-6}$ \\
\hline 1949227.0 & 1949266.5 & 39.5 & $20.3 \times 10^{-6}$ \\
\hline 1949232.0 & 1949266.3 & 34.3 & $17.6 \times 10^{-6}$ \\
\hline 2728940.0 & 2728969.1 & 29.1 & $10.7 \times 10^{-6}$ \\
\hline 3508676.0 & 3508670.9 & -5.1 & $-1.5 \times 10^{-6}$ \\
\hline 3898543.0 & 3898521.7 & -21.3 & $-5.5 \times 10^{-6}$ \\
\hline 3898569.0 & 3898538.9 & -30.1 & $-7.7 \times 10^{-6}$ \\
\hline 3118814.0 & 3118829.3 & 15.3 & $4.9 \times 10^{-6}$ \\
\hline 2339075.0 & 2339119.9 & 44.9 & $19.2 \times 10^{-6}$ \\
\hline 1559369.0 & 1559412.9 & 43.9 & $28.1 \times 10^{-6}$ \\
\hline 779713.8 & 779708.7 & -5.1 & $-6.5 \times 10^{-6}$ \\
\hline 389872.8 & 389858.4 & -14.4 & $-37.0 \times 10^{-6}$ \\
\hline 389868.0 & 389859.5 & -8.5 & $-21.9 \times 10^{-6}$ \\
\hline 1559379.0 & 1559415.0 & 36.0 & $23.1 \times 10^{-6}$ \\
\hline 1949227.0 & 1949270.5 & 43.5 & $22.3 \times 10^{-6}$ \\
\hline 2339080.0 & 2339120.1 & 40.1 & $17.2 \times 10^{-6}$ \\
\hline 3898543.0 & 3898528.1 & -14.9 & $-3.8 \times 10^{-6}$ \\
\hline 3898557.0 & 3898531.6 & -25.4 & $-6.5 \times 10^{-6}$ \\
\hline 2339081.0 & 2339120.9 & 39.9 & $17.1 \times 10^{-6}$ \\
\hline 1949225.0 & 1949269.0 & 44.0 & $22.6 \times 10^{-6}$ \\
\hline 1559372.0 & 1559413.3 & 41.3 & $26.5 \times 10^{-6}$ \\
\hline 389865.0 & 389858.3 & -6.7 & $-17.1 \times 10^{-6}$ \\
\hline \multicolumn{2}{|c|}{$\begin{array}{l}\text { Average } \\
\text { S.D. of the mean }\end{array}$} & $\begin{array}{r}13.0 \\
5.8\end{array}$ & $\begin{array}{l}3.3 \times 10^{-6} \\
4.2 \times 10^{-6}\end{array}$ \\
\hline
\end{tabular}

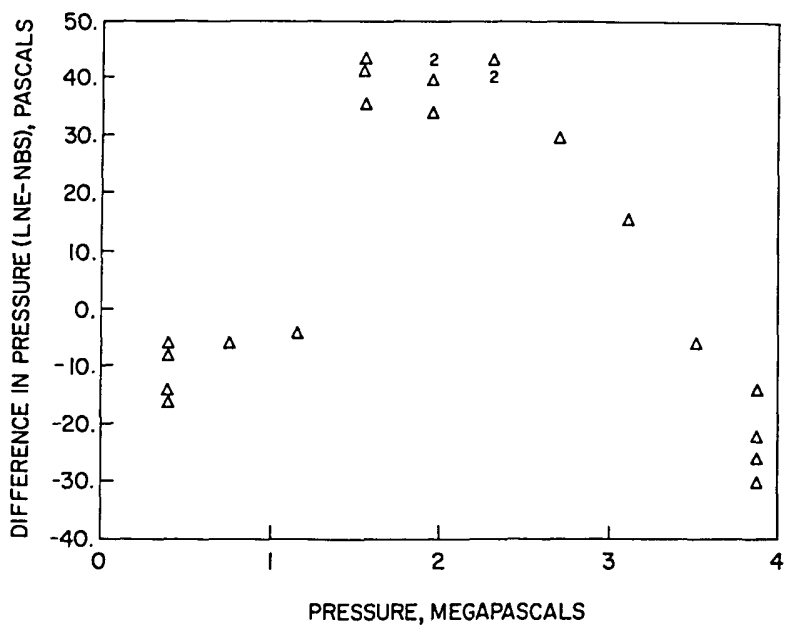

FIGURE 2. Plot of differences in pressure computed by LNE and NBS versus pressure.

jacket pressure for zero clearance on the NBS gage. Using smoothed values for the zero clearance pressure removes the indicated shift and changes the calculated area by one ppm, much less than the estimated uncertainty of the gage. 
Both methods of expressing the results of the intercomparison show significantly better agreement between the two gages than the estimated systematic uncertainty of either gage (NBS $30 \mathrm{ppm}$ and LNE $24 \mathrm{ppm}$ ). The differences observed, $6.4 \mathrm{ppm}$ by area comparison and $3.3 \mathrm{ppm}$ by pressure comparison, indicate that the two different methods of calculating effective areas are well verified at this pressure range.
We thank R. Touzin and J. C. Legras of LNE for their participation in the intercomparison.

\section{References}

[1] Tilford, C. R.; Martin, D. A high sensitivity gas/oil pressure separator, to be published in R.S.I.

[2] Heydemann, P. L. M.; Welch, B. E. Experimental thermodynamics. Vol. II Chapter 4, Part 3. Piston Gages, Editors: LeNeindre and Vodar, Butterworths 1975. 